\title{
Evaluation of Correlations between Underlying Disease and Port Complications
}

\section{Evaluation von Zusammenhängen zwischen Grunderkrankung und Portkomplikationen}

Authors

Affiliation
U. Teichgräber, S. N. Nagel, S. Kausche

Division of Diagnostic and Interventional Radiology II, Jena University Hospital

\section{Key words}

- vascular

interventional procedures

catheters received 8.3.2013

accepted $\quad 11.9 .2013$

\section{Bibliography}

DOI http://dx.doi.org/

10.1055/s-0033-1356040

Published online: 2014

Fortschr Röntgenstr 2014; 186: 496-500 @ Georg Thieme Verlag KG Stuttgart · New York . ISSN 1438-9029

\footnotetext{
Correspondence

\section{Prof. Dr. Ulf Teichgräber}

Institut für Diagnostische und Interventionelle Radiologie, Universitätsklinikum Jena Erlanger Allee 101 07747 Jena Germany

Tel.: ++ 49/3641/9324831

Fax: ++ 49/36 41/9324832

ulf.teichgraeber@

med.uni-jena.de
}

\section{Abstract \\ $\nabla$}

Purpose: Evaluation of correlations between underlying disease and port complications. Materials and Methods: Retrospective analysis of a data set of 3160 port systems, which had been interventionally implanted over a period of 10 years. Of these, 1393 were included in the final evaluation. The 7 most common underlying diseases and port-induced complications were considered. Port-related thrombotic events, port pocket infections as well as the port-induced sepsis were evaluated and classified as either early or late complications.

Results: In 1393 ports, 131 experienced complications. Of these, $22.1 \%(n=29)$ were early and $79.6 \%(n=102)$ late complications. The overall incidence rate of late complications was $0.253 / 1000$ observed days. It differed significantly between the underlying diseases $(\mathrm{p}<0.001)$ and was significantly lower in colon carcinoma when compared with pancreatic $(\mathrm{p}=0.049)$, gastric $(\mathrm{p}=0.012)$ and bronchial carcinoma $(p=0.042)$. The incidence rate of the port sepsis between the underlying diseases also differed significantly $(p=0.006)$ and had the highest rate in gastric and bronchial carcinoma. The occurrence of a thrombotic event also showed a significant difference in the incidence rates between the underlying diseases $(\mathrm{p}=0.045)$ and was highest in pancreatic and gastric carcinoma.

Conclusion: There are significant differences in the incidences of complications between the underlying diseases. Knowledge about this can help to improve the port-care and to take specific preventive measures.

Key Points:

- significant differences in the incidences of port complications between underlying diseases
- incidence rate of late complications significantly lower in colon carcinoma compared to pancreatic, gastric and bronchial carcinoma

- highest incidence rate of port sepsis in gastric and bronchial carcinoma

- highest incidence rate of thrombotic events in pancreatic and gastric carcinoma

- studies on specific prophylactic measures required

Citation Format:

- Teichgräber U, Nagel SN, Kausche S Evaluation of Correlations between Underlying Disease and Port Complications. Fortschr Röntgenstr 2014; 186: 496-500

\section{Zusammenfassung}

$\nabla$

Ziel: Evaluation von Zusammenhängen zwischen Grunderkrankung und Portkomplikationen.

Material und Methode: Retrospektive Auswertung aus einem Gesamtdatensatz von 3160 Portsystemen, welche über einen Zeitraum von 10 Jahren interventionsradiologisch implantiert worden waren. Von diesen gingen 1393 in die endgültige Auswertung ein. Die 7 häufigsten Grunderkrankungen und portinduzierte Komplikationen wurden gegenübergestellt. Betrachtet wurden dabei portbedingte thrombotische Ereignisse, Porttascheninfektionen und die portinduzierte Sepsis, wobei Früh- und Spätkomplikationen unterschieden wurden.

Ergebnisse: Bei 1393 Ports traten 131 Komplikationen auf. Hiervon waren $22,1 \%(n=29)$ Frühund 79,6\% (n=102) Spätkomplikationen. Die Gesamtinzidenzrate der Spätkomplikationen betrug 0,253/1000 Beobachtungstage. Sie unterschied sich signifikant zwischen den einzelnen Grunderkrankungen ( $p<0,001)$ und zeigte beim Kolonkarzinomen eine signifikant niedrigere Inzidenzrate gegenüber dem Pankreas- $(p=0,049)$, 
dem Magen- $(p=0,012)$ und dem Bronchialkarzinom $(p=0,042)$. Die Inzidenzrate der Portsepsis zwischen den Grunderkrankungen unterschied sich ebenfalls signifikant $(p=0,006)$ und war beim Magen- sowie Bronchialkarzinom am größten. Für das Auftreten eines thrombotischen Ereignisses zeigte sich ebenfalls ein signifikanter Unterschied der Inzidenzraten zwischen den einzelnen Grunderkrankungen $(p=0,045)$ und war dabei beim Pankreas- sowie Magenkarzinom am größten.

Schlussfolgerung: Es bestehen signifikante Unterschiede der Inzidenzen von Komplikationen zwischen den einzelnen Grunderkrankungen. Das Wissen hierüber kann helfen, die Portpflege zu verbessern und ggf. gezielte, präventive Maßnahmen zu ergreifen.

\section{Introduction}

$\nabla$

Over the past few decades, port systems have been used as indwelling venous catheter systems. Their area of application is very broad, ranging from therapeutic applications for chemotherapy, parenteral nutrition, administration of antibiotics, fluid replacement to diagnostic purposes such as taking blood samples and administering contrast agent for medical imaging [ 1 -5]. Of these examples, administering chemotherapy drugs is by far the most common indication for implanting a port system.

The different implantation techniques are commonly known and established, while the associated advantages and risks have been extensively discussed and described. Numerous articles have focused on the complication rates associated with the implantation [6-9], and the therapy options for port complications have already been repeatedly examined [10 - 12].

It is also known that the various chemotherapy regimens used in treating the particular underlying diseases entail side effects of variying degrees. A common, undesired effect is a compromised immune system, which increases the risk of infection. One of the most serious complications posed by an implanted port system is the appearance of port-induced sepsis $[13,14]$.

It is also known that an advanced degree of metastasis or malignant tumor with a high one-year mortality rate (e.g. pancreatic cancer) entails elevated thrombophilia $[15,16]$, which can in turn increase the risk of catheter lumen occlusion.

This retrospective study aims to evaluate correlations between underlying disease and port complications. The results should contribute to formulating disease-specific management for the use and care of port systems for the purpose of minimizing complications and ensuring the longest possible usability of the system.

\section{Material and methods}

$\nabla$

Data was collected in a monocentric, retrospective study covering a period of 10 years (January 1, 2000 through December 31, 2009).

Our interventional radiology division implanted a total of 3160 ports in ten years. The preferred implantation technique was using ultrasound-guided access via the right internal jugular vein and infraclavicular implantation of the port capsule followed by anchoring to the pectoral fascia. To ensure a follow-up observation period of at least one year, data collection was scheduled to end on December 31, 2009.

Over 100 different referral diagnoses (ICD-10) were recorded. To obtain meaningful group parameters for statistical processing, only the 7 most common clinical pictures were observed.

Port-related thrombotic events and infections were evaluated, the latter being further subdivided into port pocket infections and port-induced sepses.

\section{Definitions}

Per the recommendations Society of Interventional Radiology (SIR), complications were divided into early complications ( $24 \mathrm{~h}$ to $30 \mathrm{~d}$ post op) and late complications ( $>30 \mathrm{~d}$ post op) depending on when they appeared.

Catheter-associated thrombotic events can appear as a) mural thrombi at the catheter tip, b) thrombi occluding the catheter lumen and c) fibrin coatings.

Port pocket infections manifest themselves as local erythema with overheating and tenderness upon palpation that can involve the formation of pus during a later stage.

Port system-induced sepsis is defined by SIR as an infection of unknown focus, the symptoms of which subside within 48 hours of port explantation [17].

Only port systems that had reached an end point were included in the evaluation. End points included the appearance of complications, port explantation, patient death during the observation period as well as reaching the follow-up observation time with an implanted port system. Upon reaching an endpoint, the port system was not subjected to further observation.

The catheter observation period was the interval of time between port implantation and the respective endpoint.

\section{Port imaging in cases of port dysfunction}

All patients referred with "port dysfunction" were examined by our interventional radiologists in the angiosuite.

Prior to the examination, all patients were provided with oral and written information.

Following sterile preparation, patients were fitted with a port needle or any port needle present on the port system was used. Antegrade and retrograde testing of the port system was performed by injecting $10 \mathrm{ml}$ of $\mathrm{NaCl}$.

If mildly elevated infusion pressure was all it took to break up the thrombotic formation, then the intervention was deemed as successfully completed following a final flushing.

If the dysfunction was not remedied, then 5 to $10 \mathrm{ml}$ of contrast agent were injected via the port system (hence "port imaging"). Using digital subtraction angiography (DSA), the superior vena cava was tested for patency and normal flow of contrast agent. The system was finally flushed with 1000 I.U. of heparin. If no patency was established, then lysis was attempted by subsequently performing another round of port imaging. If this proved unsuccessful, then the system was explanted. 


\section{Data analysis and statistical methods} $\nabla$

Data was collected via the radiological information system (RIS) Robsys, the Orbis database (Orbis Open Med, AGFA AG, Bonn) as well as the hospital-wide SAP database (SAP for Healthcare, SAP AG, Walldorf).

Date of birth, sex, underlying disease, implantation indication, implantation modalities and the point in time of port complications were ascertained.

The Poisson-Regression model was employed to examine the influence of the underlying disease on the incidences of each examined complication. If the underlying disease was found to have a significant influence on incidence, a post-hoc pairwise comparison of the underlying diseases was undertaken using a Bonferroni-Holm correction. Data analysis was performed using the software SPSS Statistics 21.9 (IBM, USA). Significance was set at 0.05.

\section{Results}

$\nabla$

A total of 1393 port systems were evaluated, the seven most common underlying diseases being presented in - Table 1. Total observation period was 403.019 days. In total 131 (9.4\%) complications appeared. 0 Fig. 1 presents the respective frequencies of the appearing complications, dived into early and late events.

The incidence rates of early complications among the individual underlying disease vary significantly $(p=0.019)$. In relation to underlying disease, early complications showed the following distribution: Breast carcinoma (7/121, 5.8\%), ovarian carcinoma $(5 / 116,4.3 \%)$, colorectal carcinoma (7/172, 4.0\%), bronchial carcinoma (6/226, $2.7 \%)$ and pan- creatic carcinoma (4/427, 0.9\%). However, pairwise comparison of the underlying diseases showed no significantly higher incidence rate for any of the underlying diseases. No early complications were recorded for gastric carcinoma or non-Hodgkin's lymphoma.

The incidence rate of the appearing late complications (overall $0.253 / 1000$ days of observation) varied significantly among the individual underlying diseases $(\mathrm{p}<0.001)$, with a significantly lower incidence rate being observed in colorectal carcinoma compared to pancreatic $(p=0.049)$, bronchial $(\mathrm{p}=0.042)$ and gastric carcinoma $(\mathrm{p}=0.012), \diamond$ Table 2 . The incidence rate for port sepsis varied significantly $(\mathrm{p}=0.006)$ among the observed underlying diseases, being greatest for gastric carcinoma (0.285/1000 days of observation) and bronchial carcinoma (0.260/1000 days of observation). With regard to the appearance of thrombotic events, there was likewise significant difference among the individual underlying diseases $(\mathrm{p}=0.045)$, with pancreatic carcinoma (0.216/1000 days of observation) and gastric carcinoma $(0.175 / 1000$ days of observation) having the highest incidence rates.

\section{Discussion \\ $\nabla$}

As the results of this and other studies demonstrate, portassociated thrombotic events represent one of the most common type of port complications [18-20]. When it comes to underlying disease, our study found pancreatic carcinoma to have the highest rate of incidence port-associated thrombotic events, which is consistent with the findings of Chew et al. [21]. To our knowledge, there are no studies to date that have examined thrombosis in and at

\begin{tabular}{|lccccc|}
\hline underlying disease & $\mathbf{n}$ & \% & days of observation & average & median \\
\hline pancreatic carcinoma & 427 & 30.7 & 86.737 & 203 & 169 \\
\hline bronchial carcinoma & 226 & 16.2 & 35.702 & 158 & 121 \\
\hline gastric carcinoma & 211 & 15.1 & 57.886 & 274 & 216 \\
\hline colorectal carcinoma & 172 & 12.3 & 88.590 & 515 & 538 \\
\hline breast carcinoma & 121 & 8.7 & 27.020 & 223 & 115 \\
\hline non-Hodgkin lymphoma & 120 & 8.6 & 54.080 & 451 & 379 \\
\hline ovarian carcinoma & 116 & 8.3 & 53.004 & 457 & 402 \\
\hline total & 1393 & 100 & 403.019 & 289 & 191 \\
\hline
\end{tabular}

Table 1 Observation times of port systems in relation to the underlying disease.

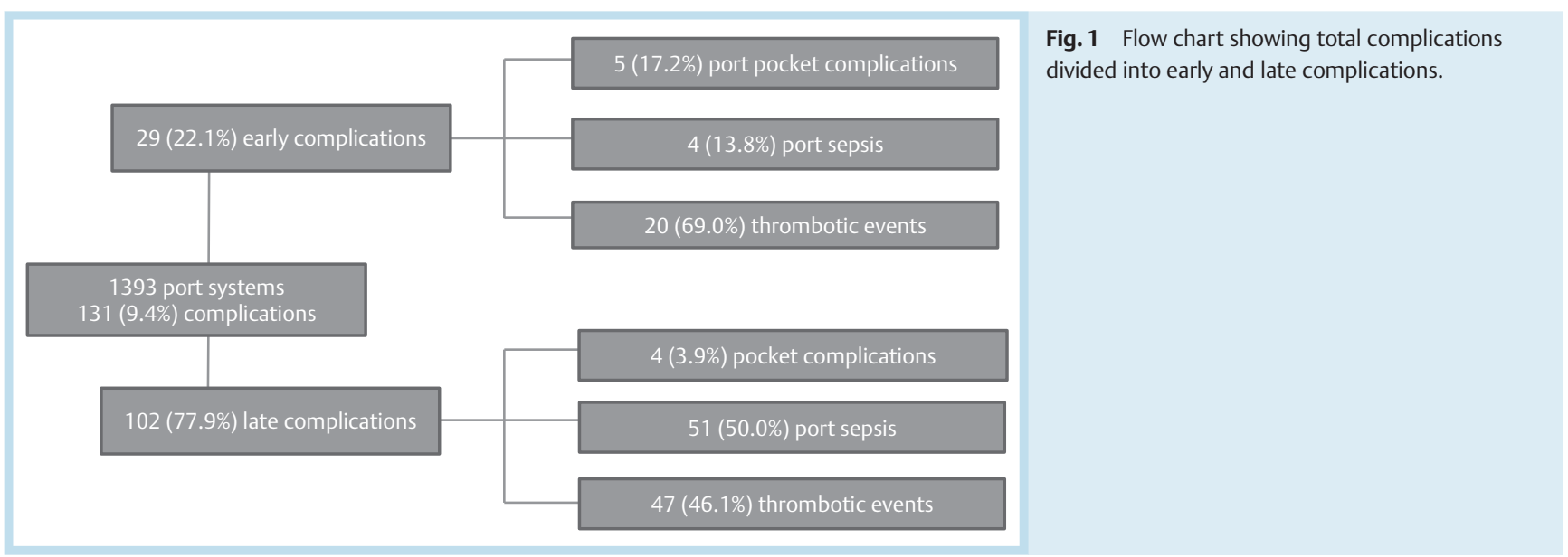


Table 2 Late complications in relation to the underlying disease.

\begin{tabular}{|c|c|c|c|c|c|c|c|c|c|c|c|c|c|}
\hline \multirow[b]{2}{*}{$\begin{array}{l}\text { underlying } \\
\text { disease }\end{array}$} & \multirow[b]{2}{*}{$\mathbf{n}$} & \multicolumn{3}{|c|}{ port pocket infection } & \multicolumn{3}{|c|}{ thrombotic events } & \multicolumn{3}{|c|}{ port-associated sepsis } & \multicolumn{3}{|c|}{ total } \\
\hline & & $\mathbf{n}$ & $\%$ & $\begin{array}{l}\text { |1000 days of } \\
\text { observation }\end{array}$ & $\mathbf{n}$ & $\%$ & $\begin{array}{l}\text { |1000 days of } \\
\text { observation }\end{array}$ & n & $\%$ & $\begin{array}{l}\text { |1000 days of } \\
\text { observation }\end{array}$ & $\mathbf{n}$ & $\%$ & $\begin{array}{l}\text { /1000 days of } \\
\text { observation }\end{array}$ \\
\hline $\begin{array}{l}\text { pancreatic } \\
\text { carcinoma }\end{array}$ & 423 & 2 & 0.5 & 0.025 & 18 & 4.4 & 0.216 & 11 & 2.7 & 0.134 & 31 & 7.3 & 0.358 \\
\hline $\begin{array}{l}\text { bronchial } \\
\text { carcinoma }\end{array}$ & 220 & 1 & 0.5 & 0.031 & 5 & 2.4 & 0.149 & 9 & 4.2 & 0.260 & 15 & 6.8 & 0.422 \\
\hline gastric carcinoma & 211 & 0 & 0.0 & 0.000 & 9 & 4.6 & 0.175 & 16 & 7.9 & 0.285 & 25 & 11.8 & 0.432 \\
\hline $\begin{array}{l}\text { colorectal } \\
\text { carcinoma }\end{array}$ & 165 & 0 & 0.0 & 0.000 & 4 & 2.5 & 0.046 & 7 & 4.3 & 0.080 & 11 & 6.7 & 0.124 \\
\hline breast carcinoma & 114 & 1 & 0.9 & 0.038 & 2 & 1.8 & 0.075 & 2 & 1.8 & 0.075 & 5 & 4.4 & 0.186 \\
\hline $\begin{array}{l}\text { non-Hodgkin's } \\
\text { lymphoma }\end{array}$ & 120 & 0 & 0.0 & 0.000 & 2 & 1.7 & 0.038 & 5 & 4.2 & 0.095 & 7 & 5.8 & 0.129 \\
\hline ovarian carcinoma & 111 & 0 & 0.0 & 0.000 & 7 & 6.4 & 0.134 & 1 & 1.0 & 0.020 & 8 & 7.2 & 0.151 \\
\hline
\end{tabular}

the port system in relation to underlying disease. The state of research on venous thromboembolic events in relation to malignant underlying diseases is significantly better. It is known that tumor cells influence coagulation and angiogenesis through different mechanisms [22]. In addition, an increased rate of embolism has been described when aggressive tumors and an increasing degree of metastasis are present $[15,21]$. The rate of embolism is additionally influenced by co-morbidities, surgical interventions and chemotherapy regimen [23]. Thromboembolic events also occur most frequently in the first month following diagnosis [23], which may be attributed to therapy beginning with surgical intervention and initial chemotherapy.

Thoroughly flushing the system prior to use is a wellknown measure for preventing port-associated thrombosis [24]. If a thrombotic formation has already appeared, lysis or fibrin-stripping are very promising methods [10]. Unless contraindicated, early systemic prophylaxis with low-molecular heparin has been discussed for preventing deep vein thrombosis in cases involving biologically aggressive tumors or metastasis [25-28]. This method may also have another positive effect by possibly reducing fibrin coatings and thrombi from the catheter tip.Subsequent studies with concomitant systemic thromboembolism prophylaxis would be required to examine to what extent this hypothesis is true.

The results of our study show that an increased number of port-related sepses has been observed particularly for gastric carcinoma. This may possibly be due to the frequently early start of parenteral nutrition via the port system and the thereby increasing risk of port-related sepsis when insufficient port system care is practiced [29]. In addition, gastric carcinoma entails a higher incidence of thrombotic events. It has been suggested that thrombotic formations on the catheter can also pose an elevated risk of catheterrelated sepsis [30, 31]. Our study is not in the position to address this statement, since port systems were observed only until the first appearing complication. In a pediatric study involving children with hematological diseases, taurolidine citrate was able to bring about a significant reduction in catheter-related sepsis [32]. A systematic survey study likewise demonstrated the advantage of heparin- or antibioticcoated catheters over non-coated catheters [33]. Independent risk factors for a port-related sepsis include, among other factors, cancer of the digestive system, cumulative number of days of catheter use and parenteral nutrition [29].

The weaknesses of our study could be that the tumor stage, the exact chemotherapy protocol, whether antithrombotic or antibiotic prophylaxis was performed and the number of times ports were used were not known. Furthermore, it cannot be ensured that all port complications were detected and recorded in the study, since treatment outside of our hospital cannot be excluded.

\section{Summary}

There are significant differences among the incidence rates of complications for individual underlying diseases. Knowing this can aid in performing systematic treatment and preventative measures, such as thromboembolism prophylaxis, to thereby prevent premature port dysfunction and possibly explantation as well. Additional studies on the effectiveness of these measures are required, however.

\section{References}

1 Moureau N, Poole S, Murdock MA et al. Central venous catheters in home infusion care: outcomes analysis in 50470 patients. J Vasc Interv Radiol 2002; 13: 1009-1016

2 Wieners G, Redlich U, Dudeck $O$ et al. First experiences with intravenous port systems authorized for high pressure injection of contrast agent in multiphasic computed tomography. Fortschr Röntgenstr 2009; 181: $664-668$

3 Gebauer B, El-Sheik M, Vogt M et al. Combined ultrasound and fluoroscopy guided port catheter implantation-high success and low complication rate. Eur J Radiol 2009; 69: 517-522

4 Lenhart M, Schatzler S, Manke C et al. Radiological placement of peripheral central venous access ports at the forearm. Technical results and long term outcome in 391 patients. Fortschr Röntgenstr 2010; 182: 20-28

5 Teichgraber UK, Nagel SN, Kausche S et al. Clinical benefit of power-injectable port systems: a prospective observational study. Eur J Radiol 81: $528-533$

6 Teichgraber UK, Kausche S, Nagel SN et al. Outcome analysis in $3160 \mathrm{im}-$ plantations of radiologically guided placements of totally implantable central venous port systems. Eur Radiol 21: 1224-1232

7 Vardy J, Engelhardt K, Cox K et al. Long-term outcome of radiologicalguided insertion of implanted central venous access port devices (CVAPD) for the delivery of chemotherapy in cancer patients: institu- 
tional experience and review of the literature. British journal of cancer 2004; 91: 1045-1049

8 Wagner HJ, Teichgraber U, Gebauer B et al. Transjugular implantation of venous port catheter systems. Fortschr Röntgenstr 2003; 175: 15391544

9 Chang DH, Boecker J, Hellmich $M$ et al. Experiences with ultrasoundguided port implantations via the lateral subclavian vein: a retrospective analysis of 1532 patients. Fortschr Röntgenstr 2012; 184: 726 733

10 Kausche S, Nagel SN, Teichgraber U. Interventional radiological imaging and treatment of port catheter dysfunctions. Fortschr Röntgenstr 2011; 183: $260-266$

11 Teichgraber UK, Gebauer B, Benter T et al. Long-term central venous lines and their complications. Fortschr Röntgenstr 2004; 176: $944-$ 952

12 Teichgraber UK, Gebauer B, Benter T et al. Central venous access catheters: radiological management of complications. Cardiovasc Intervent Radiol 2003; 26: 321 - 333

13 Groeger JS, Lucas $A B$, Thaler HT et al. Infectious morbidity associated with long-term use of venous access devices in patients with cancer. Ann Intern Med 1993; 119: 1168-1174

14 Pagano L, Tacconelli E, Tumbarello $M$ et al. Bacteremia in patients with hematological malignancies. Analysis of risk factors, etiological agents and prognostic indicators. Haematologica 1997; 82: 415-419

15 Wun T, White RH. Venous thromboembolism (VTE) in patients with cancer: epidemiology and risk factors. Cancer Invest 2009; 27: 63 - 74

16 Kakkar AK, Levine M, Pinedo HM et al. Venous thrombosis in cancer patients: insights from the FRONTLINE survey. Oncologist 2003; 8: 381 388

17 Silberzweig JE, Sacks D, Khorsandi AS et al. Reporting standards for central venous access. Technology Assessment Committee. J Vasc Interv Radiol 2000; 11: 391 - 400

18 Hsieh CC, Weng HH, Huang WS et al. Analysis of risk factors for central venous port failure in cancer patients. World J Gastroenterol 2009; 15: $4709-4714$

19 Biffi R, Orsi F, Pozzi S et al. Best choice of central venous insertion site for the prevention of catheter-related complications in adult patients who need cancer therapy: a randomized trial. Annals of oncology: of- ficial journal of the European Society for Medical Oncology/ESMO 2009; 20: $935-940$

20 Caers J, Fontaine C, Vinh-Hung V et al. Catheter tip position as a risk factor for thrombosis associated with the use of subcutaneous infusion ports. Support Care Cancer 2005; 13: 325-331

21 Chew HK, Wun T, Harvey D et al. Incidence of venous thromboembolism and its effect on survival among patients with common cancers. Arch Intern Med 2006; 166: 458-464

22 Noble S, Pasi J. Epidemiology and pathophysiology of cancer-associated thrombosis. Br J Cancer 102: S2 -S9

23 Wun T, White RH. Epidemiology of cancer-related venous thromboembolism. Best Pract Res Clin Haematol 2009; 22: 9-23

24 Nakazawa $N$. Infectious and thrombotic complications of central venous catheters. Semin Oncol Nurs 2010; 26: 121-131

25 White RH, Chew H, Wun T. Targeting patients for anticoagulant prophylaxis trials in patients with cancer: who is at highest risk? Thromb Res 2007; 120: S29-S40

26 Dutia M, White RH, Wun T. Risk assessment models for cancer-associated venous thromboembolism. Cancer 118: 3468 - 3476

27 Streiff $M B$. Diagnosis and initial treatment of venous thromboembolism in patients with cancer. J Clin Oncol 2009; 27: 4889-4894

28 Cunningham MS, Preston RJ, O'Donnell JS. Does antithrombotic therapy improve survival in cancer patients? Blood Rev 2009; 23: 129-135

29 Toure A, Vanhems $P$, Lombard-Bohas $C$ et al. Totally implantable central venous access port infections in patients with digestive cancer: Incidence and risk factors. Am J Infect Control 2012; 40: 935 - 939

30 Aitken DR, Minton JP. The "pinch-off sign": a warning of impending problems with permanent subclavian catheters. Am J Surg 1984; 148 : $633-636$

31 Hinke DH, Zandt-Stastny DA, Goodman LR et al. Pinch-off syndrome: a complication of implantable subclavian venous access devices. Radiology 1990; 177: $353-356$

32 Dumichen MJ, Seeger K, Lode HN et al. Randomized controlled trial of taurolidine citrate versus heparin as catheter lock solution in paediatric patients with haematological malignancies. J Hosp Infect 2012; 80: $304-309$

33 Gilbert RE, Harden M. Effectiveness of impregnated central venous catheters for catheter related blood stream infection: a systematic review. Curr Opin Infect Dis 2008; 21: 235-245 